\title{
A Review on Phytochemical and Pharmacological Potential of Alpinia galanga
}

\author{
Anirban Chouni, Santanu Paul*
}

\section{Anirban Chouni, Santanu Paul $^{*}$}

Laboratory of Cell and Molecular Biology, Department of Botany, University of Calcutta, Kolkata 700019, West Bengal, INDIA.

\section{Correspondence}

\section{Santanu Paul}

Laboratory of Cell and Molecular Biology, Department of Botany, University of Calcutta, Kolkata 700019, West Bengal, INDIA.

Phone No: 91-033-24614849

E-mail: spaul_1971@yahoo.com

\section{History}

- Submission Date: 14-10-2017;

- Review completed: 20-11-2017;

- Accepted Date: 20-11-2017

DOI : 10.5530/pj.2018.1.2

Article Available online http://www.phcogj.com/v10/i1

\section{Copyright}

(c) 2018 Phcog.Net. This is an openaccess article distributed under the terms of the Creative Commons Attribution 4.0

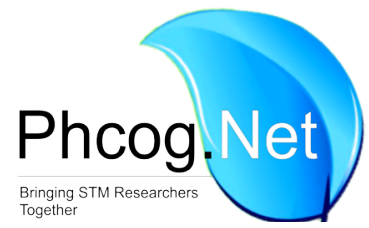

\begin{abstract}
Introduction: From the ancient Vedic era, green plants are being used for their medicinal properties to treat several diseases. Green plants represent a big source of bioactive compounds. Alpinia galanga (Linn.) of Zingiberaceae family is one amongst those medicinally important plants. Different parts of the plant are used in the treatment of many diseases for its anti-fungal, anti-tumour, antimicrobial, anti-inflammatory, anti-diabetic, antioxidant, antiulcer and many other properties. Several active compounds such as 1'S-1'-acetoxychavicol acetate, 1 'S-1'-acetoxyeuginol acetate, 1 , 8-cineol, $\alpha$-fenchyl acetate, $\beta$-farnesene, $\beta$-bisabolene, $\alpha$-bergamotene, $\beta$-pinene, $\beta$-Sitosteroldiglucoside (AG-7), $\beta$-sitsteryl Arabinoside (AG-8), 1 '-acetoxychavicol acetate (galangal acetate), p-hydroxycinnamaldehyde has been extracted from the plant. Methods: Relevant information was collected from scientific journals, books, and reports via electronic search using Medline, PubMed, Science Direct and Scopus. Results: This review provides a comprehensive report on Alpinia galanga having anti-proliferative, apoptotic, anti angiogenic as well as cytotoxic efficacy and their mode of action in vitro as well as in vivo condition. Conclusion: Considering the ability of the golden treasure present in Alpinia galanga, this review is aimed to summarize the information of the chemical constituents, pharmacological and therapeutic effects of the plant.

Key words: Alpinia galanga, 1's'-1'- Acetoxychavicolacetate, Anticancer, Antimicrobial, Bioactivity.
\end{abstract}

\section{INTRODUCTION}

Medicines derived from plant sources are widely used in traditional cultures globally and now-a-days they are getting popular as natural alternatives to synthetic chemicals. In the last few decades the use of herbal medicine has increased exponentially. Recently it is getting popular in developing and developed countries owing to its natural origin and lesser side effects. Alpinia galanga belongs to the family Zingiberaceae. The plant bears underground stems called rhizomes which have a strong aromatic smell with conspicuously nodes and internodes. ${ }^{1}$ The seed of A. galanga is used in emaciation and cleaning of the mouth, it stimulates the digestive power and appetite. It is also used as a purgative. Usually the rhizome is used as a spice and a source of essential oil. Young shoots and flowers are used as vegetable or as spice. ${ }^{2}$ The plant is broadly used in dietary intake as well as in the traditional system of medicine viz. Ayurveda, Unani, Chinese and Thai folk medicine. ${ }^{3}$ Along with an aromatic ginger like odour, it has a pungent hot and spicy taste. As the rhizome has a characteristic fragrance as well as pungency, it is widely used as a condiment for foods and local medicine in China and Thailand. ${ }^{4}$

From the leaves, stems, rhizomes and roots of Alpinia galanga, presence of essential oil is reported. Those are mono and sesquiterpene as well as (E) - methyl cinnamate in nature. They are responsible for the characteristic odour as well as for the reported use in (folk) medicine and in food products of A. galangal. ${ }^{5}$ Alpinia galanga contained flavonoids and volatile oils. ${ }^{6,7}$ The previous studies, the plant possessed many pharmacological activities, including antibacterial, antifungal, antiviral, Antiprotozoal, ${ }^{8,9}$ immunomodulatory, antioxidant effect, antidiabetic, antiplatelet, hypolipidemic and many other pharmacological effects. This review is a combination of chemical constituents, pharmacological and therapeutic effects of Alpinia galanga based on various current studies.

\section{METHODOLOGY}

The study of the literature review was carried out by searching on the electronic databases including PubMed, Science Direct, Scopus and Google Scholar for studies focusing on the biological and pharmacological activities of Alpinia galanga. All Englishlanguage articles published between 1976 and 2017 were searched using the terms 'Alpinia galanga', 'greater galangal', 'Thai galangal'. The list of references of all the relevant articles was also studied to include all reports and reviews related to the subject.

\section{TAXONOMY}

Alpinia galanga belongs to the Tribe Alpinieae of Alpinioideae subfamily under the Zingibera-
Cite this article: Chouni A, Paul S. A Review on Phytochemical and Pharmacological Potential of Alpinia galanga. Pharmacog J. 2018;10(1):9-15. 
ceae family of Zingiberales order. Alpinia galanga is known by several synonyms such as Amomum galangal, Alpinia viridiflora, Maranta galangal, Languas galangal, Languasvulgare. ${ }^{2}$ It is known by several common names such as Kulanjan in Hindi, Dhumarasmi in Kannada, Kulingjan in Bengali, Kulinjan in Gujrati, Arattha in Malayalam, Pera-rattai in Tamil, Dhoomraasmi in Kannad, Pedda-dhumpa in Telugu, Mahabaracach, SugandhaVacha, Rasna in Sanskrit, Greater galangal in English.

\section{BOTANICAL DESCRIPTION}

The plant is a perennial herb. It grows up to a height about 5 feet. Leaves are oblong-lanceolate, tuberous root, slightly aromatic. The rhizome is from $3.5-7.5 \mathrm{~cm}$ in length, and seldom more than $2 \mathrm{~cm}$ thick. The leaves are long, oblong-lanceolate, acute, glabrous, ligules are short and rounded. Flowers are greenish white in colour, bracteate, bracts are ovate lanceolate. Tubular calyx, Corolla lobes oblong, claw green, blade white, striated with red, rather more than $1 \mathrm{~cm}$ long, broadly elliptic, shortly 2-lobed at the apex, with a pair of subulate glands at the base of the apex, with a pair of subulate glands at the base of the claw. Fruit the size of the small cherry, orange red. ${ }^{10}$

\section{GEOGRAPHICAL DISTRIBUTION}

Alpinia galanga commonly found in Indonesia, India, China, and Arabic gulf areas, Malaysia, Egypt and Sri Lanka. It grows in open, sunny places, forests and brushwood. It is commonly cultivated in the mid and lowcountry in Sri Lanka. ${ }^{2}$ In India the plant is distributed in the Himalaya and Southern region of Western Ghats. ${ }^{11}$

\section{TRADITIONAL USE}

Alpinia galanga is an important medicinal plant in different traditional systems of medicine to treat several diseases, including microbial infections, inflammations, rheumatic pains, chest pain, and dyspepsia, fever, burning of the liver, kidney disease, tumours, diabetes and even HIV. ${ }^{12}$ The plant has an active role in the treatment of eczema, bronchitis, coryza, mobile, pityriasis versicolor, otitis internal, gastritis, ulcers, and cholera. The seed is used for emaciation and to clean the mouth. It stimulates the digestive power, appetite and acts as a purgative. The rhizome is generally used as a spice. It is also a good source of essential oil. The flowers and young shoots are also used as a vegetable or as a spice. ${ }^{2}$

\section{ACTIVE COMPOUNDS}

1'S-1'-acetoxychavicol acetate (ACE), isolated from Alpinia galanga is the major compound so far reported with various biological activities. ${ }^{13}$ About $80 \%$ of Alpinia galanga rhizome aqueous acetone extract were found to inhibit the release of b-hexosaminidase, as a marker of antigen-IgEmediated degranulation in RBL-2H3cells. Nine known phenylpropanoids and p-hydroxybenzaldehyde were isolated from the extract. Among them, 1'S-1'-acetoxychavicol acetate and 1'S-1'-acetoxyeugenol acetate exhibited potent inhibitory activity with $\mathrm{IC}_{50}$ values of 15 and $19 \mathrm{mM}^{14}$ Table 1. Four isomers of acetoxy cineoles (trans and cis)-2-and 3-acetoxy-1, 1, 8-cineoles has been isolated from the isolated plant of rhizome. Their structures were confirmed by comparing the retention indices by GC and the mass spectra with those of synthesized compound ${ }^{15}$ Figure 2 1'-acetoxychavicol acetate (galangal acetate) has been extracted and isolated from rhizome of Alpinia galanga. Galangal acetate was identified as the pungent principal of galangal rhizomes. The identification was done by the Gas Chromatography Analysis. ${ }^{16} \beta$-Sitosteroldiglucoside (AG-7) and $\beta$-sitsteryl Arabinoside (AG-8), has been isolated from the rhizome of Alpinia galanga and characterized by their spectral value. ${ }^{17}$
Three hydroxy-l, 8-cineole glucopyranosides, (1R, 2R, 4S)-and (1S, 2S, $4 \mathrm{R})$-trans-2-hydroxy-1, 8-cineole $\beta$-D-glucopyranoside, and (1R, 3S, 4S)trans-3-hydroxy-1, 8-cineole $\beta$-D- lucopyranoside, which are possible precursors of acetoxy-1, 8-cineole, has isolated and identified from the rhizome of the Alpinia galangal. The major active compounds found in A. galanga are 1, 8-cineol, Galangin, $\alpha$-fenchyl acetate, $\beta$-farnesene, $\beta$-bisabolene, $\alpha$-bergamotene, $\beta$-pinene, 1'S-1'-acetoxychavicol acetate, 1 'S-1'-acetoxyeuginol acetate, $\beta$-Sitosteroldiglucoside (AG-7), $\beta$-sitsterylArabinoside (AG-8), 1'-acetoxychavicol acetate (galangal acetate), p- droxycinnamaldehyde, [di-(p-hydroxy-cis-styryl)] methane. By using FAB-MS and NMR spectrometry the structures of the compounds were analyzed. The absolute configuration of each aglycone was determined by using a GC-MS analysis with a capillary column coated with a chiral stationary phase. By GC-MS analysis after preparing the trifluoroacetate derivatives of the glycosides it was found that the composition of the diastereomers of (1R, 2R, 4S)-and (1S, 2S, 4R)-trans-2-hydroxy 1,8-cineole $\beta$-D-glucopyranosides in the rhizome was determined as 3:7.18 $p$-hydroxycinnamaldehyde and [di-(p-hydroxy-cis-styryl)] methane has been isolated by the chloroform extract from the rhizome of the Alpinia galangal. ${ }^{19}$ From the roots of Alpinia galanga some endophyticactinomycetes (120) has isolated. Based on the morphology and amino acid composition of the whole-cell extracts the identification of these endophytes has done. Most of them were classified as Streptomyces sp. (82). Others were identified as Nocardia sp. (11), Microbispora sp. (3), Micromonospora sp. (2). Eight isolated were unclassified and 14 were lost during subculture. ${ }^{20} \mathrm{An}$ antimicrobial diterpene was isolated from the rhizome of Alpinia galanga. The structure was elucidated by spectral data and identified as (E) -8 beta, 17- epoxylabd-12-ene-15, 16-dial ${ }^{21}$ Table 1 . Xanthine oxidase (XO) inhibitors were isolated from the rhizome of Alpinia galanga. The compound had been identified as trans-p-coumaryldiacetate, transconiferyldiacetate, [1'S] -1'-acetoxychavicol acetate, [1'S] -1'-acetoxyeugenol acetate and 4-hydroxybenzaldehyde. ${ }^{22}$ From the rhizomes of Alpinia galanga six phenylpropanoids were obtained and their structures were identified as $(S)$-1'-ethoxy chavicol acetate $(1),(E)$-4-acetoxy cinnamyl ethyl ether (2), (E)-4-hydroxycinnamaldehyde (3), (E)-4-acetoxy cinnamyl alcohol (4), 4-acetoxy cinnamyl acetate (5), and 4, 4' [(2E, 2'E)-bis(prop2-ene)-1, 1'-oxy]-diphenyl-7, 7'-diacetate (6). By using various chromatographic methods and crystallization chemical constituents were isolated, and the chemical structures were elucidated on the basis of spectral analysis. Compounds $\mathbf{1}$ and $\mathbf{2}$ were two new phenylpropanoids. Compound 5 shows the selective cytotoxic activity on human lung adenocarcinoma cell A549 $\left(\mathrm{IC}_{50} 19.35 \mu \mathrm{mol} \cdot \mathrm{L}^{-1}\right){ }^{23}$

\section{BIOACTIVITY}

Now-a-days, Alpinia galanga is gaining lots of interest, according to the researchers' point of view. Many pharmacological studies have been conducted recently on Alpinia galanga (Figure 1). A summary of the findings is presented below:

\section{Antimicrobial Activity}

The essential oils obtained from fresh and dried rhizomes of Alpinia galanga show antimicrobial activity against g-positive bacteria. An extract from the dried rhizome shows antimicrobial activity against Trichophytonmentagrophytes. ${ }^{24}$ 1'S'-1'- acetoxychavicol acetate obtained from Alpinia galanga acts as an efflux pump inhibitor which provokes resistance in Mycobacterium and hence it acts as a new target for the discovery of anti-TB agents ${ }^{25}$ Table 1. 1'-acetoxychavicol acetate from Alpinia galanga showed antiplasmid activity against multi-drug resistant bacteria. A crude acetone extract of the rhizomes of Alpinia galanga exhibited antiplasmid activity against Salmonella typhi, Escherichia coli and vancomycin resistant Enterococcusfaecaliswith an efficiency of $92 \%, 82 \%$ and $8 \%$ respectively at $400 \mathrm{micro} \mathrm{g} / \mathrm{ml}$ SIC Table $1 .{ }^{26}$ Using Agar well diffusion method, 
cactinomycetes obtained from root of Alpinia galanga against phytopathogenic fungi was tested against Candida albicans, and phytopathogenic fungi, Colletotrichummasae and Fusariumoxysporum. The strain, Streptomyces aureofaciens CMUAc130 was the most effective in antifungal activity amongst those investigated. ${ }^{28}$ The essential oils obtained from dried A. galanga rhizomes showed effective against Staphylococcus aureus, Bacillus subtilis, Streptococcus faecalis[Enterococcus faecalis], Escherichia coli, Proteus vulgaris, Salmonella enteritidis, Saccharomyces cerevisiaeand Aspergillusniger (the MIC values ranged from 1.25 to $12,5 \mathrm{micro} 1 / \mathrm{ml}$ ) Essential oil obtained from dried rhizome is more effective than fresh one. ${ }^{29}$ Hexane, ethyl acetate, acetone or methanol extract of the rhizome of Alpinia galanga shows the anti-Phytopthoracapsiciactivities and it has the potential antifungal activity. ${ }^{30}$ In comparison of the antimicrobial potential of variety of extraction of Alpinia galanga extract such as hexane, ethyl acetate, ethanol and the essential oil respectively against swine pathogenic bacteria compose of Escherichia coli ATCC, Staphilococcus aureus ATCC, Salmonella typhimurium ATCC, Salmonella enteritidis and Pasteurellamultocida, essential oil of Alpinia galanga have the best antibacterial and bactericidal activities with minimum inhibition concentration (MIC) and minimum bactericidal concentration (MBC) to Escherichia coli ATCC, Staphilococcus aureus ATCC, Salmonella typhimurium ATCC and Salmonella enteritidisat $8 \mathrm{mg} / \mathrm{cc}$ and to Pasteurellamultocidaat $16 \mathrm{mg} / \mathrm{cc}^{31}$ From various extracts of Alpinia galanga antimicrobial activity were screened against the common food borne bacteria such as Escherichia coli, Salmonella enteriditis, Clostridiumperfringens, Staphylococcus aureus, Campylobacter jejuni, Bacillus cereus and fungi such as Saccharomyces cerevisiae, Hansenulaanomala, Mucormucedo, Candidaalbicans using disc diffusion method. All the extracts showed significant antibacterial and antifungal properties. ${ }^{32}$ Extracts from Alpinia galanga flowers shows the largest zone of inhibition of Micrococcus leteus. $^{33}$

\section{Antifungal activity}

The ethanolic extracts of Alpinia galanga found to possess good antifungal activities against Trichophytonlongifusus. ${ }^{34}$ Diterpene compound, (E)-8 $\beta$, 17-epoxylabd-12-ene-15, 16-dialsynergistically enhanced the antifungal activity of quercetin and chalcone against Candida albicans. ${ }^{21}$ Strong antifungal activities of n-Hex and DCM fractions of Alpinia galanga has been demonstrated by zone of inhibition assay. High phenolic and flavonoid content and strong free radical scavenging activity of the fractions of A.galanga has been observed. ${ }^{35}$

\section{Antiinflammatory activity}

Antiallergic principles have reported from Alpinia galanga rhizome. 80\% aqueous acetone extract of the rhizomes of Alpinia galanga expressed the inhibition of the release of beta -hexosaminidase, as a marker of antigenIgE-mediated degranulation in RBL-2H3 cells. 1'S-1'-acetoxychavicol acetate and $1^{\prime} S-1^{\prime}$-acetoxyeugenol acetate exhibit potent inhibitory activity. Additionally, ear passive cutaneous anaphylaxis reactions in mice and the antigen-IgE-mediated TNF- $\alpha$ and IL- 4 production are inhibited by $1^{\prime} S-1{ }^{\prime}$-acetoxychavicol acetate and $1^{\prime} S-1^{\prime}$-acetoxyeugenol acetate. In RBL-2H3 cells, both participate in the late phase of type I allergic reactions. ${ }^{14}$ Purification of the acetone extract of Alpinia galanga produces $p$-hydroxy cinnamaldehyde, which is a potential therapeutic agent for treatment of Osteoarthritis as it influences human chondrocytes Table $1 .{ }^{36}$ Ethanolic extract of Alpinia galanga rhizome has scientifically validated anti-inflammatory screening technique on rats by carrageenan induced pleurisy. The results obtained indicate that the ethanolic extract has significant activity in rats. Hence, the ethanolic extract of A. galanga rhizome has potential anti-inflammatory activity. ${ }^{37}$ Anti-inflammatory activity of Petroleum ether, Chloroform, Methanolic and Aqueous methanolic (1:1) extracts of Alpinia galangal. Willd has been investigated in carrageenan induced paw edema in Wistar rats and compared to a positive control drug, Ibuprofen. Methanolic extract of Alpinia galanga showed maximum inhibition of $79.51 \%$ on carrageenan induced rat paw edema. ${ }^{38}$

\section{Hepatotoxicity}

It has observed that the hepatoprotective effect of the crude extract of Alpinia galanga at 200 and $400 \mathrm{mg} \mathrm{kg-1}$ treated paracetamol induced hepatotoxicity in rats. ${ }^{39}$

\section{Immunomodulator}

Hot water polysaccharide extracts of Alpinia galanga (L.) Willd. Shows marked stimulating effect on the reticulo-endothelial system (RES) and increased the number of peritoneal exudate cells (PEC), and spleen cells of mice. Hence, hot water polysaccharide extracts of $A$. The challenge has immuno-stimulating activity. ${ }^{40}$

\section{Anti-Diabetic activity}

The extracts of the rhizome of Alpinia galanga in rabbits show hypoglycemic activity on their blood glucose levels. In normal rabbits, powdered rhizome and its methanol and aqueous extracts significantly lowered the blood glucose. ${ }^{41}$ Methanolic extract of aerial parts of Alpinia galanga was effective in controlling blood glucose level and improve lipid profile in euglycemic as well as diabetic rats. ${ }^{42}$ The methanolic extracts of Alpinia galanga shows a considerable inhibition of the haemoglobin glycosylation. The extract of the plant inhibits the activities of $\alpha$-amylase and a-glucosidase in a concentration dependent manner which indicate that the plant possesses considerable in vitro antidiabetic activity. ${ }^{43}$

\section{Anti-Oxidant activity}

Antioxidant activity has shown by extract of Alpinia galanga. 50\% ethanol in water was studied for its antioxidant activity and composition in comparison with two other samples based on a water extract and the essential oil. By using 2, 2-diphenyl-1-picrylhydrazyl (DPPH) and oxygen radical absorbance capacity (ORAC) the antioxidant activities were measured. Highest DPPH free radical scavenging ability was reported from the ethanolic extract. Highest ORAC value observed when compared to the water extract and the essential oil. ${ }^{44}$ Antioxidant activity of 1 '-acetoxychavicol acetate and its related compounds has been reported from the rhizomes of Alpinia galanga. ${ }^{45}$ Methanol extracts of Alpinia galanga has been evaluated for total phenolic content (TPC) and antioxidant activities (AOA). Using 1, 1-diphenyl-2-picrylhydrazyl (DPPH), reducing power $(\mathrm{RP})$, ferrous ion chelating as well as $\beta$-carotene bleaching assays the AOA has been investigated. A.galanga leaves and flowers showed highest chelating and $\beta$-carotene bleaching abilities. So the leaves of the plant may serve as potential dietary source of natural antioxidant. ${ }^{33}$

\section{Anticancer property}

An aqueous acetone extract from the fruit of Alpinia galanga demonstrated inhibitory effects on melanogenesis in theophylline-stimulated murine B16 melanoma $4 \mathrm{~A} 5$ cells $\left(\mathrm{IC}_{50}=7.3 \mu \mathrm{g} / \mathrm{ml}\right) .{ }^{46}$ In the investigation of the potential of Alpinia galanga rhizomes to induce cytotoxic and apoptotic effects in the cultured human breast carcinoma cell line, (MCF-7) in comparison with the non-malignant (MRC-5) cells cultured in DMEM medium, the percentage of apoptotic cells was determined by flow cytometry using Annexin-V fluorescein isothiocyanate. It was found that Alpinia galanga induced apoptosis in MCF-7 cells, as determined by flow cytometry. ${ }^{47}$ The active compound, 1'S'-1'- acetoxychavicol acetate were found to provide inhibition of the growth of oral squamous cell carcinoma in in vitro or in vivo by inhibition of the constitutive activation of $\mathrm{NF}-\kappa \mathrm{B}$ through suppression of IKK $\alpha / \beta$ activation Figure 3 . The effect of the compound is also correlated with a down-regulation of NF- $\kappa \mathrm{B}$ regulated 
gene (FasL and Bim), including proinflammatory (NF- $\kappa B$ and COX-2) and proliferative (cyclin D1) biomarkers in tumor tissue Table $1 .{ }^{48}$ Alpinia galanga was found to cause antitumor activity. Active compounds from A. galanga such as $1^{\prime}$-acetoxychavicol acetate and $1^{\prime}$-acetoxyeugenol acetate were isolated as antitumour principles against Sarcoma 180 ascites in mice Table $1 .^{49}$ The high dose of methanolic extract of $A$. galanga treated albino mice showed no estrogenic activity rather showed decrease uterine wet weight as well as morphologically constricted uterine horns which clearly suggests anti-estrogenic activity. ${ }^{50} 1$ '-acetoxychavicol acetate (ACA) obtained from the rhizomes of Alpinia galanga induces apoptosis in myeloid leukemic cells via independent dual pathways. ACA has potential as a novel therapeutic agent for the treatment of myeloid leukaemia. It is evident that low-dose ACA dramatically inhibited cellular growth of leukemic cells by inducing apoptosis. NB4 promyelocytic leukemic cells are sensitive to ACA. Reactive oxygen species production triggers ACA-induced apoptosis. In NB4 cells, ACA-induced apoptosis is in association with the loss of mitochondrial transmembrane potential $(\Delta \Psi \mathrm{m})$ and activation of caspase-9, suggesting that ACA-induced death signalling is mediated through a mitochondrial oxygen stress pathway. In addition, ACA activated Fas-mediated apoptosis by inducing of casapse- 8 activity Table $1 .^{51} 1$ 'S-1'-acetoxychavicol acetate (ACA) isolated from A. galanga, induced cytotoxicity in various cancer cells, including cervical cancer in combination with miR-629 and RSU1. ${ }^{52} 1$, 7-bis (4-hydroxyphenyl)-1, 4, 6-heptatrien-3-one (BHPHTO) and bisdemethoxycurcumin (BDMC) which has been isolated from A. galanga rhizome, were examined for their defectiveness on the human melanoma A2058 and showed that significantly inhibited the proliferation of melanoma cells in the cell viability assay Table 1 . The research was also taken on the tests to B16-F10 cell line and showed minor inhibitory consequences of cellular tyrosinase activities and melanin contents..$^{53}$

\section{Anti-Ulcer property}

Extract of Alpinia galanga has been studied on experimentally induced gastric ulcers in rats. At a dose of $500 \mathrm{mg} / \mathrm{kg}$ of the ethanolic extract, the intensity of gastric mucosal damage induced by pyloric ligation and hypothermic restraint stress in rats significantly reduced. The experimental result shows significant antisecretory and cytoprotectively action of A. galanga which may be responsible for its antiulcer activity. ${ }^{54}$ The potent anti-ulcer principles, 1'-acetoxychavicol acetate (1) and 1'-acetoxyeugenol acetate (2), were isolated from the seeds of Alpinia galanga and established by chemical syntheses. ${ }^{55}$ The effects of 1 'S-1'-acetoxychavicol acetate and related phenylpropanoids isolated from the rhizomes of Alpinia galanga on ethanol-induced gastric lesions in rats has been evaluated. It has been observed that, 1'S-1'-acetoxychavicol acetate and 1'S-1'-acetoxyeugenol acetate markedly inhibited the ethanolinduced gastric mucosal lesions. ${ }^{56}$

\section{RESULTS AND DISCUSSION}

Nowadays it has been recognized that several diseases are caused due to the oxidative stress. Oxidative stress generates inside the living system due to imbalance of the formation of Reactive Oxygen Species i.e. ROS and their endogenous neutralization by quenching of the free radicals. Formation of ROS is an inevitable natural process. To combat the generation of oxidative stress exogenous antioxidant is necessary to neutralize the ROS. From the above mentioned characteristics of Alpinia galanga it is clear that the plant is potentially rich in antioxidant property. Hence Alpinia galanga may be used as a good source of antioxidant. Generation of ROS is also related to cancer development. Again, it has been seen that the plant exhibits good anticancer properties in several cell lines. Apart from antioxidant and anticancer properties, the plant has antidiabetic, anti-inflammatory, anti-microbial, anti-fungal, anti-ulcer properties. So, it is clear that Alpinia galanga possesses rich phytochemical and pharmacological potentials. Compiling all the current knowledge so far we have regarding Alpinia galanga it is evident that the plant is a potential powerhouse of several lead molecules which are responsible for numerous bioactivities. Hence, isolation and identification of those lead molecules are needed for opening a new window in therapeutics of cancer biology as well as several other diseases.

\section{CONCLUSION}

From the various scientific research based on Alpinia galanga, the plant has a huge biological potential. Several chemicals present in the plant shows a wide pharmacological and medicinal property. More research and evaluation needs to be done to isolate and identify different chemicals present in the plant which will be used for innumerable application for human welfare in the near future.

\section{ACKNOWLEDGEMENT}

The authors are thankful to the Department of Biotechnology, Government of India for the financial support. The authors also thank UGC CAS programme at the department for support.

\section{CONFLICT OF INTEREST}

The authors declare that they have no conflict of interest.

\section{ABBREVIATION USED}

ACE: 1'S-1'-acetoxychavicol acetate; RBL: Rat Basophilic Leukemia; FAB-MS: Fast Atom Bombardment Mass Spectrometry; HIV: Human immunodeficiency virus; NMR: Nuclear magnetic resonance; GC-MS: Gas chromatography-mass spectrometry; TB: Tuberculosis; MIC: Minimum inhibitory concentration; MBC: minimum bactericidal concentration; DCM: Dichloromethane; TNF- $\alpha$ : tumor necrosis factor alpha; IL-4: interleukin 4; DPPH: 2, 2-diphenyl-1-picrylhydrazyl; ORAC: oxygen radical absorbance capacity; TPC: total phenolic content; AOA: antioxidant activities; $\mathbf{N F - \kappa B : ~ N u c l e a r ~ f a c t o r - \kappa B ; ~ I K K - ~} \boldsymbol{\beta}$ : inhibitor of nuclear factor kappa-B; COX-2: cyclooxygenase 2; ROS: Reactive Oxygen Species.

\section{REFERENCES}

1. Jirawan O. Effects of the Zingiberaceae spice extracts on growth and morphological changes of foodborne pathogens. Doctor of Philosophy in Food Technology Suranaree University of Technology Academic Year 2005. ISBN. 2005;974-533463-4.

2. Arambewela L, Wijesinghe A. Sri Lankan Medicinal Plant Monographs and Analysis - Alpinia galanga. 2006.

3. Yang $X$, Eilerman RG. Pungent principal of Alpinia galangal $(L)$ Swartz and its applications. Food Chem.1999;47(4):1657-62. doi:10.1021/jf9808224.

4. Chudiwal AK, Jain DP, Somani RS. Alpinia galanga Willd- An overview on phytopharmacological properties. Indian Journal of Natural Products and Resources. 2010;1:143-9.

5. Jirovetz L, Buchbauer G, Shafi MP, Leela NK. Analysis of the essential oils of the leaves, stems, rhizomes and roots of the medicinal plant Alpinia galanga from southern India. Acta Pharm. 2003;53(2):73-82.

6. Pal Jain A, Singh Pawara R, Lodhia S, Singhaia A. Immunomodulatory and antioxidant potential of Alpinia galanga Linn. rhizomes. Pharmacogn Commun. 2012;2(3):30-7. doi:10.5530/pc.2012.3.7.

7. Yu JG. Identification of the chemical components of two Alpine species, Zhongyao tong bao Beijing, China. 1981;13(6):34-6

8. De-Pooter HL, Omar MN, Coolsaet BA, Schamp NM. The essential oil of greater galanga (Alpinia galanga) from Malaysia. Phytochemistry.1985;24(1):93-6. Doi:10.1016/S0031-9422(00)80814-6.

9. Kiuchi F, Keniji M, Itano Y, Ito M, Honda G, Qui TK, et al. Screening of Natural Medicines Used in Vietnam for Trypanocidal Activity. Nat Med. 2002;56(2):64-8

10. Gupta RK. Medicinal and Aromatic Plants. $1^{\text {st }}$ ed. CBS Publisher and Distributors Pvt. Ltd. New Delhi. 2010:468-9.

11. Khare CP. Alpinia galanga - An Important Medicinal Plant: A review. A Dictionary of Indian Medicinal Plant, Published by Springer India Pvt. Ltd. 2007;37.

12. Ramesh KV, Garima S, Pradeep S, Jha KK, Khose RL. Alpinia galanga _ an 
important medicinal plant: a review, Der Pharm. Sin. 2011;2(1):142-54.

13. Baradwaj RG, Rao MV, Senthil Kumar T. Novel purification of 1'S-1'-Acetoxychavicol acetate from Alpinia galanga and its cytotoxic plus antiproliferative activity in colorectal adenocarcinoma cell line SW480. Biomed Pharmacother. 2017:91:485-93. doi:10.1016/j.biopha.2017.04.114.

14. Matsuda $H$, Morikawa T, Managi $H$, Yoshikawa M. Antiallergic principles from Alpinia galanga: structural requirements of phenylpropanoids for inhibition of degranulation and release of TNF- $\alpha$ and IL-4 in RBL-2H3 cells. Bioorg Med Chem Lett. 2003;13(19):3197-202. doi:https://doi.org/10.1016/S0960-894X(03)00710-8.

15. Kubota K, Nakamura K, Kobayashi A, Amaike M. Acetoxy-1,8-cineoles as Aroma Constituents of Alpinia galanga Willd. J Agric Food Chem. 1998;46(12):5244-7. doi:10.1021/jf9804239.

16. Yang $X$, Eilerman RG. Pungent principal of Alpinia galanga $(L)$ Swartz and its applications. J Agric Food Chem. 1999;47(4)1657-62. doi:10.1021/jf9808224.

17. Jaju SB, Indurwade NH, Sakarkar DM, Ali M, Fuloria NK, Duragkar NJ. Isolation of ß-sitosterodiglucoside and ß-Sitsteryl arabinoside from rhizomes Alpinia galanga. Asian J Chem. 2009;21(3):2350-6.

18. Someya $Y$, Kobayashi $A$, Kubota $K$. Isolation and identification of trans-2- and trans-3-hydroxy-1,8-cineole glucosides from Alpinia galanga. Biosci Biotechno Biochem. 2001;65(4):950-3. doi:10.1271/bbb.65.950.

19. Barik BR, Kundu AB, Dey AK. Two phenolic constituents from Alpinia galanga rhizomes. Phytochemistry. 1987;26(7):2126-7. doi:10.1016/S0031-9422(00)81779-3.

20. Taechowisan T, Wanbanjob A, Tuntiwachwuttikul P, Taylor WC. Identification of Streptomyces sp. Tc022 an endophyte in Alpinia galanga and the isolation of actinomycin D. Ann Microbiol. 2006;56(2):113-7.

21. Haraguchi $H$, Kuwata $Y$, Inada $K$, Shingu $K$, Miyahara $K$, Nagao $M$, et al. Antifungal activity from Alpinia galanga and the competition for incorporation of unsaturated fatty acids in cell growth. Planta Med. 1996;62(4):308-13. doi:10.1055/s-2006-957890

22. Noro T, Sekiya T, Katoh M, Oda Y, Miyase T, Kurayanagi M. Inhibitors of xanthine oxidase from Alpinia galanga. Chem Pharm Bull. 1988;36(1):244-8. doi:10.1248/ cpb.36.244.

23. Zhao L, Chen LY, Liang JY. Two new phenylpropanoids isolated from the rhizomes of Alpinia galanga. Chin J Nat Med. 2012;10(5):370-3. doi:10.1016/ S1875-5364(12)60074-0.

24. Janssen AM, Scheffer JJ. Acetoxychavicol Acetate, an Antifungal Component of Alpinia galanga 1. Planta Med. 1985;51(06):507-11. doi:10.1055/s-2007-969577.

25. Roy SK, Pahwa S, Nandanwar H, Jachak SM. Phenylpropanoids of Alpinia galanga as efflux pump inhibitors in Mycobacterium smegmatis mc2 155. Fitoterapia. 2012;83(7):1248-55. doi:https://doi.org/10.1016/j.fitote.2012.06.008.

26. Latha C, Shriram VD, Jahagirdar SS, Dhakephalkar PK, Rojatkar SR. Antiplasmid activity of 1???-acetoxychavicol acetate from Alpinia galanga against multidrug resistant bacteria. J Ethnopharmacol. 2009;123(3):522-5. doi:10.1016/j. jep.2009.03.028.

27. Rao K, Ch B, Narasu LM, Giri A. Antibacterial Activity of Alpinia galanga (L) Willd Crude Extracts. Appl Biochem Biotechnol. 2010;162(3):871-84. doi:10.1007/ s12010-009-8900-9

28. Taechowisan T, Lumyong S. Activity of endophyticactinomycetes from roots of ZingiberofficinaleandAlpinia galanga against phytopathogenic fungi, Annals of Microbiology. 2003;53(3):291-8.

29. Thuy Quynh VT, Duszkiewicz - Reinhard W. Antimicrobial activity of essentia oils from fresh and dried Alpinia galanga rhizomes. J Essent Oil Bear Plants. 2004;7:165-70. doi:10.1080/0972-060X.2004.10643385.

30. Pompimon W, Jomduang J, Prawat U, Mankhetkorn S. Anti-Phytopthora capsici activities and potential use as antifungal in agriculture of Alpinia galanga Swartz, Curcuma longa Linn, Boesenbergia pandurata Schut and Chromolaena odorata: bioactivities guided isolation of active ingredients. Am J Agric Biol Sci. 2009;4(1):83-91.

31. Yamsakul $P$, Kongkhaew S, Yano T, Sukprasitch V, Prakattagomol W, Ogonoki S. The antibacterial and bactericidal activity of Alpinia galanga extracts to referent strain of pathogenic bacteria of pig in vivo. Proceedings of the $47^{\text {th }}$ Kasetsart University Annual Conference, Kasetsart, 17-20 March 2009, Subject: Veterinary Medicine. 2009;208-15.

32. Sunilson JAJ, Suraj R, Rejitha G, Anandarajagopal K, Kumari AVAG, Promwichit P. In vitro antimicrobial evaluation of Zingiber officinale, American. Journal of Food Technology. 2009;4(5):192-200.

33. Wong LF, Lim YY, Omar M. Antioxidant and antimicrobial activities of some alpina species. J food biochem. 2009;33(6):835-51. doi:10.1111/j.17454514.2009.00258.x.

34. Khattak S, Saeed-ur-Rehman, Ullah-Shah H, Ahmad W, Ahmad M. Biologica effects of indigenous medicinal plants Curcuma longa and Alpinia galanga. Fitoterapia. 2005;76(2):254-7. doi:https://doi.org/10.1016/j.fitote.2004.12.012.

35. Sharma AS, Jain S, Bhatnagar M, Ghosal S. Inte ernational In vitro ro antibac cterial, an tifungal, antioxida ant and an ntihemoly ytic activit ties of Alp pinia galan anga Intr roduction. Int J Phytomedicine. 2015;7(1):78-89.

36. Phitak T, Choocheep K, Pothacharoen P, Pompimon W, Premanode B, Kongtawelert P. The effects of p-hydroxycinnamaldehyde from Alpinia galanga extracts on human chondrocytes. Phytochemistry. 2009;70(2):237-43. doi:https://doi.org/10.1016/j.phytochem. 2008.11.010.

37. Subash KR, Prakash GB, Reddy KV, Manjunath K, Rao KU. Anti-inflammatory activity of ethanolic extract of Alpinia galanga in carrageenan induced pleurisy rats. Natl J Physiol Pharm Pharmacol. 2016;6(5):468-70. doi:10.5455/ njppp.2016.6.0719013072016.

38. Unnisa A, Parveen TD. Anti-inflammatory and acute toxicity studies of the extracts from the rhizomes of Alpinia galanga Willd. Der Pharm Sin. $2011 ; 2(2): 361-7$

39. Hemabarathy B, Budin SB, Feizal V, others. Paracetamol hepatotoxicity in rats treated with crude extract of Alpinia galanga. J Biol Sci. 2009;9(1):57-62.

40. Bendjeddou D, Lalaoui K, Satta D. Immunostimulating activity of the hot watersoluble polysaccharide extracts of Anacyclus pyrethrum, Alpinia galanga and Citrullus colocynthis. J Ethnopharmacol. 2003;88(2):155-60. doi:https://doi. org/10.1016/S0378-8741(03)00226-5

41. Akhtar MS, Khan MA, Malik MT. Hypoglycaemic activity of Alpinia galanga rhizome and its extracts in rabbits. Fitoterapia. 2002;73(7):623-8. doi:https://doi. org/10.1016/S0367-326X(02)00235-6.

42. Verma RK, Mishra G, Singh P, Jha KK, Khosa RL. Anti-diabetic activity of methanolic extract of Alpinia galanga Linn. aerial parts in streptozotocin induced diabetic rats. Ayu. 2015:36(1):91-5. doi:10.4103/0974-8520.169006.

43. Heera P, Inbathamizh L, Ramachandran J. An in vitro study on Antidiabetic activity of different solvent extract from Alpinia galanga. 2014;2:1-10.

44. Mahae N, Chaiseri S. Antioxidant Activities and Antioxidative Components in Extracts of Alpinia galanga (L.) Sw. Kasetsart J - Nat Sci. 2009;43:358-69.

45. Kubota K, Ueda Y, Yasuda M, Masuda A. Occurrence and antioxidative activity of 1 '-acetoxychavicol acetate and its related compounds in the rhizomes of Alpinia galanga during cooking. In: Spanier AM, Shahidi F, Parliment TH, Mussinan C Ho C-T, Contis ET, editors. Food Flavors Chem. Adv. New Millenn., The Royal Society of Chemistry. 2001;274(1):601-10. doi:10.1039/9781847550859-00601.

46. Manse $Y$, Ninomiya K, Nishi R, Kamei I, Katsuyama $Y$, Imagawa T, et al. Melanogenesis inhibitory activity of a 7-O-9'-linked neolignan from Alpinia galanga fruit. Bioorg Med Chem. 2016;24(23):6215-24. doi:https://doi.org/10.1016/j. bmc.2016.10.001.

47. Samarghandian S, Hadjzadeh MAR, Afshari JT, Hosseini M. Antiproliferative activity and induction of apoptotic by ethanolic extract of Alpinia galanga rhizhome in human breast carcinoma cell line. Bio Med Central Complement Altern Med. 2014;14(1):192. doi:10.1186/1472-6882-14-192

48. In LLA, Arshad NM, Ibrahim H, Azmi MN, Awang K, Nagoor NH. 1'-Acetoxychavicol acetate inhibits growth of human oral carcinoma xenograft in mice and potentiates cisplatin effect via proinflammatory microenvironment alterations. Bio Med Central Complement Altern Med. 2012;12(1):179. doi:10.1186/1472-6882 12-179.

49. Itokawa H, Morita H, Sumitomo T, Totsuka N, Takeya K. Antitumour principles from Alpinia galanga. Planta Med. 1987;53(1):32-3. doi:10.1055/s-2006-962611.

50. Sing YR, Kalita D, Chandra J. Effect of methanolic extract of Alpinia galanga from Manipur (India) on uterus of ovariectomised C3H albino mice. Inter Res J Pharm. 2012;15(2):420-7.

51. Ito K, Nakazato T, Murakami A. Induction of apoptosis in human myeloid leukemic cells by 1'-acetoxychavicol acetate through a mitochondrial- and Fas mediated dual mechanism. Clin Cancer Res. 2004;10(6):2120-30.

52. Phuah NH, Azmi MN, Awang K, Nagoor NH. Suppression of micro RNA-629 enhances sensitivity of cervical cancer cells to 1 'S-1'-acetoxychavicol acetate via regulating RSU1. Onco Targets Ther. 2017;10:1695-705. doi:10.2147/OTT. S117492.

53. Lo CY, Liu PL, Lin LC, Chen YT, Hseu YC, Wen ZH, et al. Antimelanoma and Antityrosinase from Alpinia galangal Constituents. Sci World J. 2013;2013:1-5. doi:10.1155/2013/186505

54. Al-Yahya MA, Rafatullah S, Mossa JS, Ageel AM, Al-Said MS, Tariq M. Gastric antisecretory, antiulcer and cytoprotective properties of ethanolic extract of Alpinia galanga willd in rats. Phyther Res. 1990;4(3):112-4. doi:10.1002/ ptr.2650040308.

55. Mitsui S, Kobayashi S, Nagahori $H$, Ogiso A Constituents from seeds of Alpinia galanga Wild, and their anti-ulcer activities. Chem Pharm Bull (Tokyo). 1976;24(10):2377-82.

56. Matsuda H, Pongpiriyadacha Y, Morikawa T, Ochi M, Yoshikawa M. Gastroprotective effects of phenylpropanoids from the rhizomes of Alpinia galanga in rats: structural requirements and mode of action. Eur J Pharm. 2003:471(1):59-67 doi:10.1016/S0014-2999(03)01785-0. 
GRAPHICAL ABSTRACT

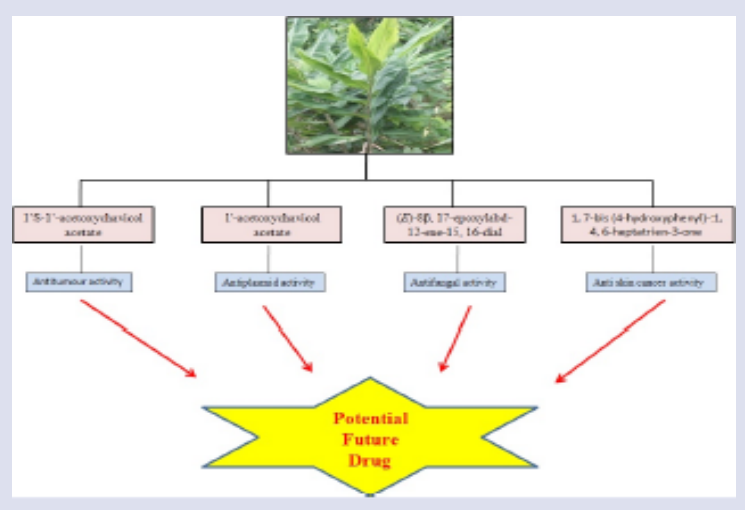

SUMMARY

- Alpinia galanga (Linn.) is a medicinally important plant belongs to Zingiberaceae family.

- Chiefly the rhizome part of the plant is used in the treatment of many diseases for its anti-fungal, anti-tumour, antimicrobial, anti-inflammatory, anti-diabetic, antioxidant, anti-ulcer and many other properties.

- Several active compounds has been extracted from the plant which shows bioactivity.

- Isolation and identification of the bioactive lead molecules may be used in therapeutics of cancer biology as well as several other diseases.

\section{ABOUT AUTHORS}

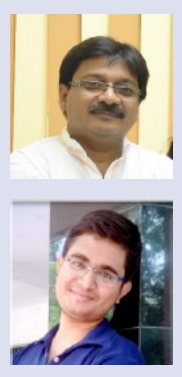

Dr. Santanu Paul is an Associate Professor at the Department of Botany; University of Calcutta; India.

Anirban Chouni is a Junior Research Fellow at the Department of Botany; University of Calcutta; India.

Cite this article: Chouni A, Paul S. A Review on Phytochemical and Pharmacological Potential of Alpinia galanga. Pharmacog J. 2018;10(1):9-15. 